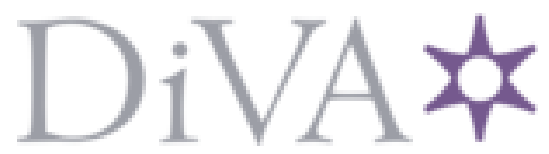

http://www.diva-portal.org

This is the published version of a paper published in Indoor + Built Environment.

Citation for the original published paper (version of record):

Hesaraki, A., Holmberg, S. (2013)

Demand-controlled ventilation in new residential buildings: consequences on indoor air quality and energy savings.

Indoor + Built Environment

http://dx.doi.org/10.1177/1420326X13508565

Access to the published version may require subscription.

N.B. When citing this work, cite the original published paper.

Permanent link to this version:

http://urn.kb.se/resolve?urn=urn:nbn:se:kth:diva-123568 


\section{Indoor and Built Environment}

http://ibe.sagepub.com/

\section{Demand-controlled ventilation in new residential buildings: consequences on indoor air quality and energy savings \\ Arefeh Hesaraki and Sture Holmberg \\ Indoor and Built Environment published online 20 November 2013 \\ DOI: $10.1177 / 1420326 \times 13508565$ \\ The online version of this article can be found at: \\ http://ibe.sagepub.com/content/early/2013/11/17/1420326X13508565}

\section{Published by: \\ @SAGE}

http://www.sagepublications.com

On behalf of:

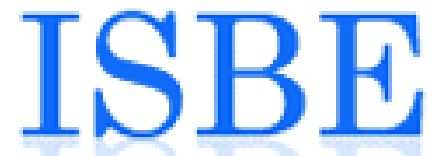

International Society of the Built Environment

Additional services and information for Indoor and Built Environment can be found at:

Email Alerts: http://ibe.sagepub.com/cgi/alerts

Subscriptions: http://ibe.sagepub.com/subscriptions

Reprints: http://www.sagepub.com/journalsReprints.nav

Permissions: http://www.sagepub.com/journalsPermissions.nav

>> OnlineFirst Version of Record - Nov 20, 2013

What is This? 


\title{
Demand-controlled ventilation in new residential buildings: consequences on indoor air quality and energy savings
}

Indoor and Built Environment 0 (0) 1-12

(C) The Author(s) 2013

Reprints and permissions: sagepub.co.uk/

journalsPermissions.nav DOI: 10.1177/1420326X13508565 ibe.sagepub.com

@SAGE

\author{
Arefeh Hesaraki and Sture Holmberg
}

\begin{abstract}
The consequences on indoor air quality (IAQ) and potential of energy savings when using a variable air volume (VAV) ventilation system were studied in a newly built Swedish building. Computer simulations with IDA Indoor Climate and Energy 4 (ICE) and analytical models were used to study the IAO and energy savings when switching the ventilation flow from $0.375 \mathrm{I} \cdot \mathrm{s}^{-1} \cdot \mathrm{m}^{-2}$ to $0.100 \mathrm{I} \cdot \mathrm{s}^{-1} \cdot \mathrm{m}^{-2}$ during unoccupancy. To investigate whether decreasing the ventilation rate to $0.1 \mathrm{I} \cdot \mathrm{s}^{-1} \cdot \mathrm{m}^{-2}$ during unoccupancy, based on Swedish building regulations, BBR, is acceptable and how long the reduction can last for an acceptable IAQ, four strategies with different VAV durations were proposed. This study revealed that decreasing the flow rate to $0.1 \mathrm{I} \cdot \mathrm{s}^{-1} \cdot \mathrm{m}^{-2}$ for more than $4 \mathrm{~h}$ in an unoccupied newly built building creates unacceptable IAQ in terms of volatile organic compounds concentration. Hence, if the duration of unoccupancy in the building is more than $4 \mathrm{~h}$, it is recommended to increase the ventilation rate from $0.100 \mathrm{I} \cdot \mathrm{s}^{-1} \cdot \mathrm{m}^{-2}$ to $0.375 \mathrm{I} \cdot \mathrm{s}^{-1} \cdot \mathrm{m}^{-2}$ before the home is occupied. The study showed that when the investigated building was vacant for $10 \mathrm{~h}$ during weekdays, increasing the ventilation rate $2 \mathrm{~h}$ before occupants arrive home (low ventilation rate for $8 \mathrm{~h}$ ) creates acceptable IAQ conditions. In this system, the heating requirements for ventilation air and electricity consumption for the ventilation fan were decreased by $20 \%$ and $30 \%$, respectively.
\end{abstract}

\section{Keywords}

Controlled ventilation system, Energy performance, IDA ICE 4, Indoor air quality, Variable air volume

Accepted: 18 September 2013

\section{Nomenclature}

$\mathrm{ACH}$ air changes per hour

BBR Swedish National Board of Housing, Building and Planning

$c$ pollutant concentration in the room, ppm

$c_{\mathrm{h}}$ heat capacity, $\mathrm{J} \cdot \mathrm{kg}^{-1} \cdot{ }^{\circ} \mathrm{C}^{-1}$

$c_{\text {inlet }}$ pollutant concentration in the inlet ventilation air, ppm

$c_{\mathrm{o}}$ pollutant concentration in the room at start $(t=0), \mathrm{ppm}$

$\mathrm{CO}_{2}$ carbon dioxide

$f_{\varepsilon}$ freshness efficiency, $\%$

h hour

$\dot{m}$ emission rate, $\mathrm{kg} \cdot \mathrm{h}^{-1}$

$m$ mass of the material, $\mathrm{kg}$

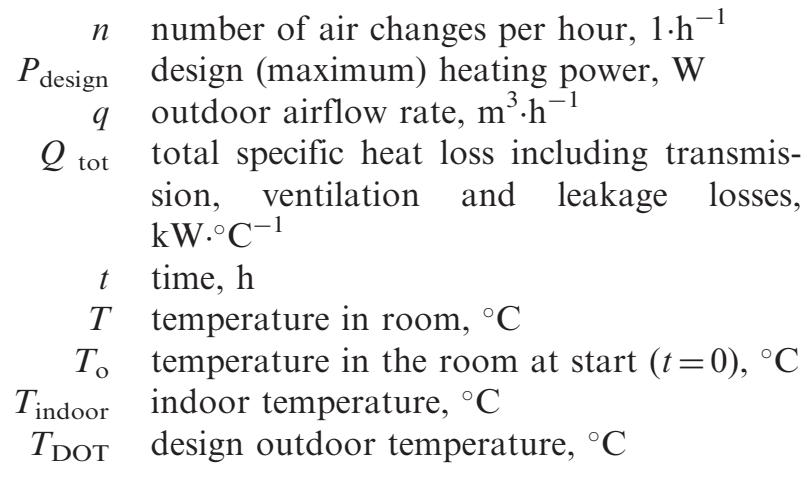

Division of Fluid and Climate Technology, School of Architecture and the Built Environment, KTH Royal Institute of Technology, Stockholm, Sweden

Corresponding author:

Arefeh Hesaraki, Brinellvägen 23, 10044 Stockholm, Sweden. Email: arefeh.hesaraki@byv.kth.se 


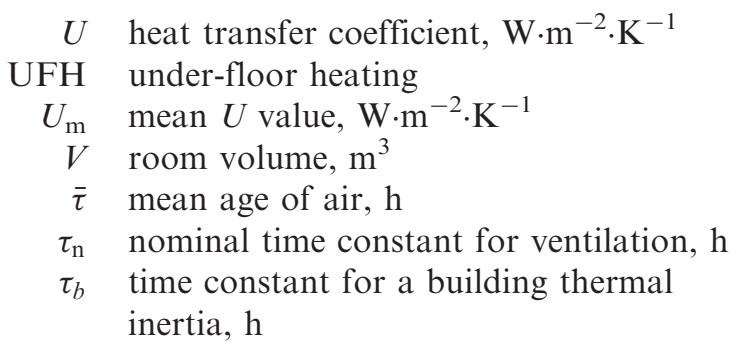

\section{Introduction}

The main goal of a ventilation system is to create acceptable indoor air quality (IAQ) and thermal comfort taking into account health, comfort and productivity of inhabitants. ${ }^{1}$ There are various types of ventilation systems, for example, natural ventilation, mechanical ventilation or a combination of them, that is, hybrid ventilation. Depending on factors such as IAQ requirements, outdoor climate and cost, one type is preferred over the others. Ventilation airflow can be supplied to the room by constant air volume (CAV) or variable air volume (VAV). The VAV system is already dominant in industrial, commercial, school and office buildings, ${ }^{2}$ owing to the different occupancy levels during a day and unpredictable fluctuations in $\mathrm{CO}_{2}$ concentration. However, in residential buildings VAV is not a very common system.

It should be noted that a VAV system is only feasible if the pollution level and demand for ventilation air vary over time. Swedish building regulations, BBR, ${ }^{3}$ recommend a minimum ventilation rate of $0.351 \cdot \mathrm{s}^{-1} \cdot \mathrm{m}^{-2}$ of floor area in all occupied residential dwellings; corresponding to $0.5 \mathrm{ACH}$ in a room with $2.5 \mathrm{~m}$ height. In BBR, it is also mentioned that when no one is at home, the ventilation rate can be decreased to $0.101 \cdot \mathrm{s}^{-1} \cdot \mathrm{m}^{-2}$. A base constant ventilation rate, that is, $0.101 \cdot \mathrm{s}^{-1} \cdot \mathrm{m}^{-2}$, is required in order to take into account the constant pollutant sources, for example, building materials and furniture.

In current residential buildings, people go to work or school from morning until afternoon. This gives opportunity for reducing the ventilation rate during non-occupancy hours. However, existing residential ventilation systems with constant ventilation rate are in conflict with ventilation on demand. This results in periods with wasting energy on heating unnecessary airflow. Hence, in order to achieve energy-efficient residential buildings the ventilation rate should be varied according to the demand, depending on occupancy level or pollutant emission.

VAV systems have become popular due to improved energy efficiency in comparison with CAV systems. ${ }^{4}$ In residential buildings many studies, ${ }^{5-9}$ have focused on this aspect of VAV and demand-controlled ventilation
(DCV) systems. These studies based on site measurements, simulations and analytical models have shown that depending on the control system, 5-60\% of initial energy demand could be saved in residential buildings. The performance of four different DCV ventilation strategies was studied ${ }^{5}$ based on relative humidity $(\mathrm{RH})$, $\mathrm{CO}_{2}$, presence of occupants and combination of all variables. In conclusion, $60 \%$ of the energy was saved when controller set point values were used for all variables.

In addition, the performance of DCV systems in multi-zone office buildings was investigated by several studies. ${ }^{10-13}$ Nassif ${ }^{11}$ developed a robust $\mathrm{CO}_{2}$-based multi-zone DCV, which controlled the $\mathrm{CO}_{2}$ concentration in supply air to be low enough to meet the ASHRAE Standard 62.1-2010 requirements. In this proposed system, the outdoor air damper was modulated accordingly. Investigations were performed on various US locations. These results showed better IAQ and energy savings compared with the DCV system in which the $\mathrm{CO}_{2}$ concentration was based on exhaust air control. In addition, the performance and control of a $\mathrm{CO}_{2}$ and enthalpy-based DCV system in hot and humid climate were investigated in terms of IAQ and cooling energy savings. ${ }^{12}$ Their control with neural network was based on occupancy level and energy content of both supply and exhaust air, that is, enthalpy-based air-side economizer. Also, Yang et al. ${ }^{15}$ conducted studies on performance of the four strategies of VAV system including occupancy detection, indoor temperature and enthalpy-based outdoor airflow economizer cycle with supply air temperature reset. Their investigation was based on thermal comfort, energy savings and $\mathrm{CO}_{2}$ concentration. Here, it was difficult to optimize all parameters simultaneously.

As mentioned, there are many variables applicable for controlling the airflow rate in VAV systems, for example, $\mathrm{CO}_{2}$ concentration, $\mathrm{RH}$, room temperature or occupancy detection. $\mathrm{A} \mathrm{CO}_{2}$ indicator is only appropriate with unpredictable variations in occupancy, and when the occupancy is high, ${ }^{7}$ for example, in schools or commercial buildings. In addition, RH depends on the temperature and absorption or desorption of moisture in building materials, and it may cause erroneous indication of ventilation rate based on the inhabitants' demand. $^{7}$ In buildings with stable periods of occupancy, time control or occupancy detection could be appropriate control variables.

To control airflow rate in a mechanical ventilation system, ventilation fan speed can be adjusted in several ways based on occupancy detection. The simplest way would be manual control; this method requires a manual switch to adjust the ventilation fan speed, and responsibility is left to the occupants. Most likely, the occupants prefer this and feel more comfortable when they themselves have control of their own environment. 
Another method could be controlling the ventilation fan speed with a timer, that is, clock control. With clock control the occupancy period is easily predictable, and the speed of ventilation fan can be adjusted accordingly. Another system could be a link to an infra-red sensor control system within the house to detect the presence of people. However, in all these control systems, the IAQ in terms of indoor pollutant gases such as $\mathrm{CO}_{2}$ or volatile organic compounds (VOCs) should be considered.

In Sweden, the ventilation rate in an unoccupied building is allowed to decrease to $0.11 \cdot \mathrm{s}^{-1} \cdot \mathrm{m}^{-2}$, but there is still the question of how long the ventilation rate can remain at the decreased level taking into account the IAQ and thermal comfort.

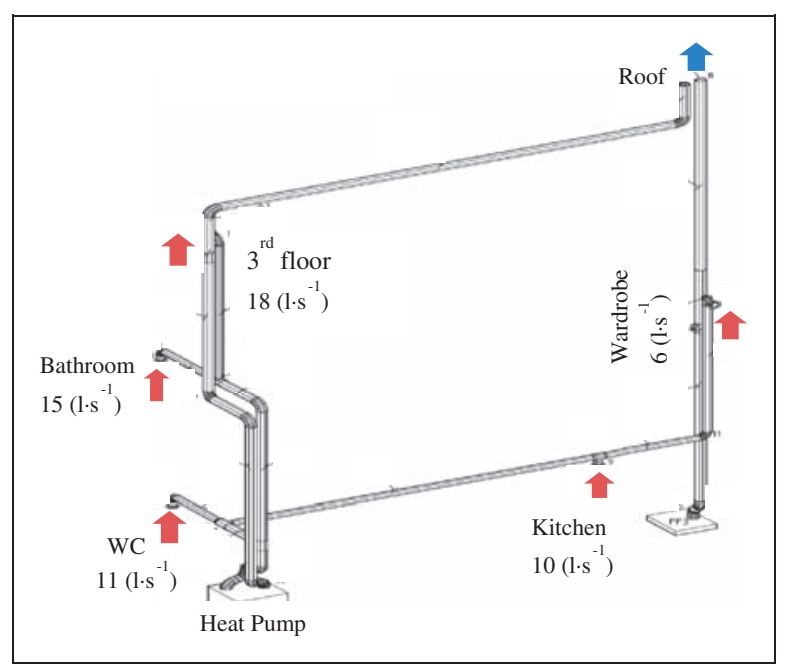

Figure 1. Schematic of exhaust air CAV ventilation system in studied building.
To answer this question a newly built Swedish building with a CAV ventilation system was chosen. Then the ventilation rate was modelled to decrease from $0.3751 \cdot \mathrm{s}^{-1} \cdot \mathrm{m}^{-2}$ to $0.1001 \cdot \mathrm{s}^{-1} \cdot \mathrm{m}^{-2}$ during unoccupancy. Finally, the influence of this VAV concept on IAQ in terms of mean age of air, $\mathrm{CO}_{2}$ and $\mathrm{VOC}$ concentrations, as well as the potential of energy savings, were evaluated. The authors motivated a VAV system in the building by the fact that occupants spent approximately $14 \mathrm{~h}$ of $24 \mathrm{~h}$ per weekday and $20 \mathrm{~h}$ per weekend-day in the building. ${ }^{14}$

Heating requirements for CAV ventilation in the investigated building accounted for approximately $60 \%$ of total space and ventilation heating demand. So, by implementing a VAV system there is a potential for saving energy by decreasing this demand. In this study, the controlled airflow rate was based on occupancy detection. The ventilation fan speed thus increased when home was occupied and decreased when the building was empty.

\section{Description of the building}

The investigated building was $160 \mathrm{~m}^{2}$ with three storeys including kitchen, bathroom, living room and bedrooms. The total building volume was $390 \mathrm{~m}^{3}$. A mechanical CAV exhaust ventilation system extracted in total $601 \cdot \mathrm{s}^{-1}$ from exhaust devices in the kitchen $\left(101 \cdot \mathrm{s}^{-1}\right)$, wardrobe $\left(61 \cdot \mathrm{s}^{-1}\right)$, bathroom and toilet $\left(261 \cdot \mathrm{s}^{-1}\right)$, and third floor $\left(181 \cdot \mathrm{s}^{-1}\right)$. The mechanical ventilation system is shown in Figure 1. This corresponds to $0.3751 \cdot \mathrm{s}^{-1} \cdot \mathrm{m}^{-2}$ of floor area and fulfilled BBR requirements. ${ }^{3}$ A simplified drawing of the dwelling illustrating the schematic of airflow and heating systems on the different floors is shown in Figure 2. Exhausted air was replaced by fresh outdoor air

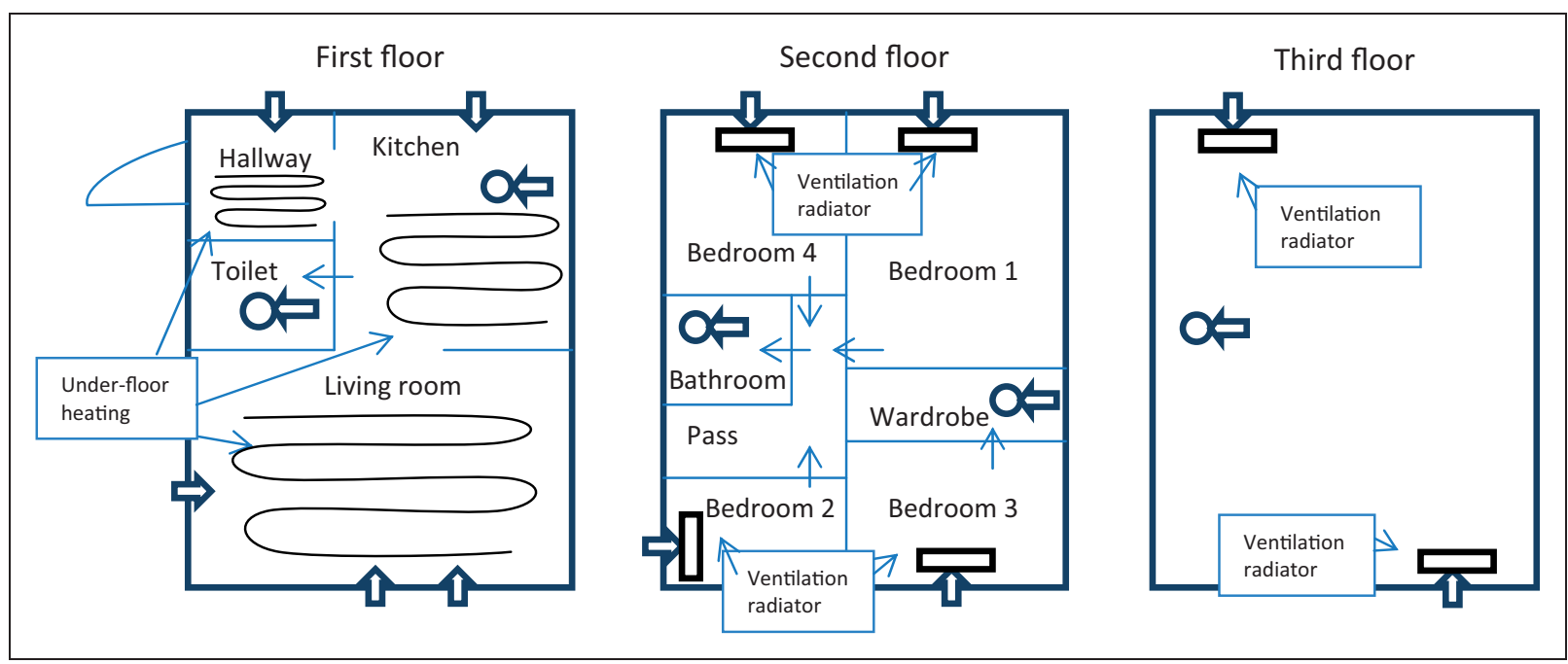

Figure 2. Building plan showing the schematic of airflow and heating systems. 
Table 1. Floor area and supply/exhaust airflow rates in different zones of the building; the average supply/exhaust flow rate is seen in the last column.

\begin{tabular}{|c|c|c|c|c|c|c|c|c|c|c|c|c|c|}
\hline Zone & $\begin{array}{l}\text { Living } \\
\text { room }\end{array}$ & Kitchen & Hallway & Bedroom & 1 Bedroom 2 & 2 Bedroom 3 & 3 Bedroom 4 & + Toilet & Bathroom & Wardrobe & Pass & $\begin{array}{l}\text { Third } \\
\text { floor }\end{array}$ & Total \\
\hline Area, $\mathrm{m}^{2}$ & 24.0 & 13.1 & 6.8 & 13.1 & 8.0 & 8.2 & 12.1 & 6.1 & 4.4 & 2.9 & 7.3 & 54.0 & 160.0 \\
\hline Supply, $1 \cdot \mathrm{s}^{-1} \cdot \mathrm{m}^{-2}$ & 0.6 & 0.3 & 0.6 & 0.5 & 0.5 & 0.5 & 0.5 & 0.0 & 0.0 & 0.0 & 0.0 & 0.3 & 0.375 \\
\hline Exhaust, $1 \cdot \mathrm{s}^{-1} \cdot \mathrm{m}^{-2}$ & 0.0 & 0.8 & 0.0 & 0.0 & 0.0 & 0.0 & 0.0 & 1.8 & 3.4 & 2.1 & 0.0 & 0.3 & 0.375 \\
\hline
\end{tabular}

entering through inlets in bedrooms and living room due to constant negative pressure in the building created by exhaust fan. Supply devices were placed on the external walls above windows in the living room, kitchen and hallway on the first floor, and behind radiators in bedrooms on the upper floors. This kind of radiator is called 'ventilation radiator' since the vent supply is located behind the radiator and is connected to it for preheating of incoming air. ${ }^{16}$ Table 1 shows the area and airflow rate in each zone.

The investigated building was a newly built Swedish house with low transmission loss through construction due to a high level of airtightness and very low mean $U$ value, that is, $U_{\mathrm{m}}$ was $0.28 \mathrm{~W} \cdot \mathrm{m}^{-2} \cdot \mathrm{K}^{-1}$. This value was lower than the limited $U_{\mathrm{m}}$ assigned by $\mathrm{BBR}$, that is, $0.40 \mathrm{~W} \cdot \mathrm{m}^{-2} \cdot \mathrm{K}^{-1}$.

The critical factor with respect to the efficiency of the VAV system and energy savings is the airtightness of the building. A high infiltration rate will increase the uncontrolled air volume causing need for additional heating. A blower door test showed that the airtightness of the investigated building was $0.631 \cdot \mathrm{s}^{-1} \cdot \mathrm{m}^{-2}$ (external surface) under $50 \mathrm{~Pa}$ pressure difference between indoor and outdoor.

\section{Method}

The main evaluation tool of this study was the IDA Indoor Climate and Energy (ICE) 4 simulation program. ${ }^{17}$ IDA ICE 4 is a dynamic program used to predict the energy consumption, thermal comfort and IAQ based on building properties defined by the user. ${ }^{18}$ In IDA ICE 4, a mathematical model is created to calculate the heating and cooling load in a building by simultaneous dynamic simulation of heat transfer and airflow. The results of IDA ICE 4 have been validated in several studies. ${ }^{19-22}$ In IDA ICE 4 , it is possible to define different airflow rates in supply and exhaust parts for different zones in the form of a VAV or CAV system. In addition to the clock-controlled fan speed and pressure, the VAV model can be controlled by humidity, $\mathrm{CO}_{2}$ and temperature for each zone.

The investigated building was modelled in the same geometry as the actual building with a CAV system, see Figure 3 . In addition, with the purpose of investigating

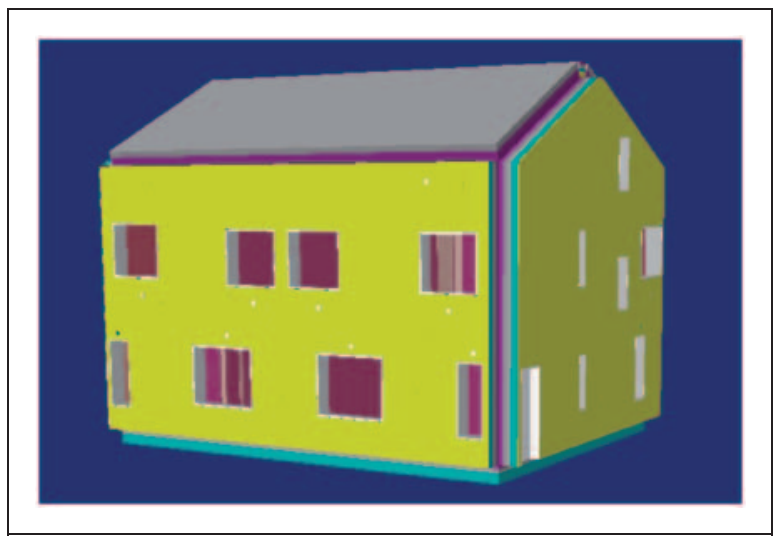

Figure 3. Simulation model frame of the house in the IDA ICE software.

the IAQ and the potential for energy savings, the building was modelled with a VAV system as well. The building modelled was divided into 12 zones considering different rooms with different ventilation exhaust and supply flow rates. The ventilation system was modelled as a mechanical exhaust system. To define the supply air, the opening was considered on the external walls in bedrooms, living room, kitchen, hallway and third floor, and the exhaust devices were modelled in the kitchen, bathroom, toilet, wardrobe and third floor.

In the modelled VAV system, the ventilation rate was switched between two flow rates, that is, normal requirements (per floor area) of $0.3751 \cdot \mathrm{s}^{-1} \cdot \mathrm{m}^{-2}$ to $\mathrm{min}$ imum requirements of $0.1001 \cdot \mathrm{s}^{-1} \cdot \mathrm{m}^{-2}$ during unoccupancy. This strategy, based on the presence of occupants, was controlled by variable ventilation fan speed. The ventilation fan speed as a result of the ventilation flow rate was decreased to $27 \%$ of the normal speed when reduced ventilation rate was needed, see Figure 4 . The value of $27 \%$ shows the ratio of 0.100 to $0.3751 \cdot \mathrm{s}^{-1} \cdot \mathrm{m}^{-2}$.

To investigate how long the reduced ventilation rate is acceptable in an unoccupied building, four different VAV duration periods were proposed. In the first system the ventilation rate was decreased during the whole period of unoccupancy from 8:00 until 18:00 


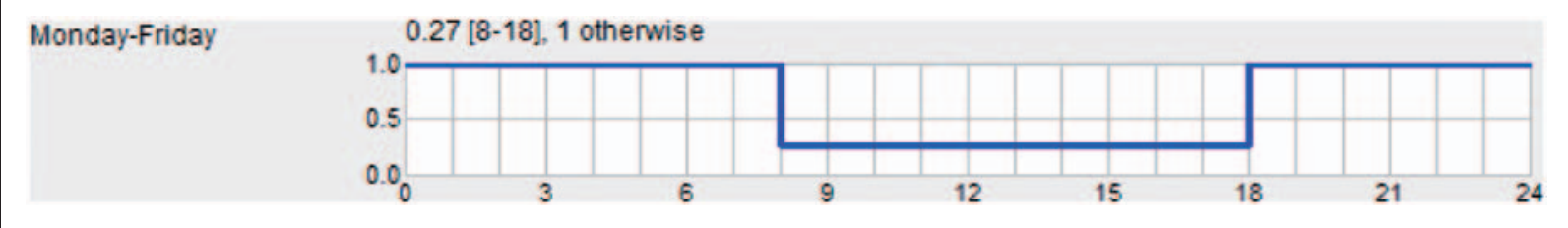

Figure 4. Profile for the ventilation fan speed for weekdays; 1 for working in full power during occupancy (18:00-8:00) and 0.27 for working with $27 \%$ of full speed during unoccupancy (8:00-18:00).

Table 2. Start and stop time and mean air change for each proposed VAV control.

\begin{tabular}{lllll}
\hline & LVR4h & LVR6h & LVR8h & LVR10h \\
\hline Start time & $8: 00$ & $8: 00$ & $8: 00$ & $8: 00$ \\
Stop time & $12: 00$ & $14: 00$ & $16: 00$ & $18: 00$ \\
Mean air change averaged over a day, $\mathrm{h}^{-1}$ & 0.48 & 0.45 & 0.42 & 0.38 \\
\hline
\end{tabular}

VAV: variable air volume.

(low ventilation rate for $10 \mathrm{~h}, \mathrm{LVR} 10 \mathrm{~h})$. In the second scenario, the ventilation rate was back to normal requirements $2 \mathrm{~h}$ before occupants entered home (low ventilation rate for $8 \mathrm{~h}$ from 8:00 until 16:00, LVR8h). The third strategy provided low ventilation rate for $6 \mathrm{~h}$ from 8:00 until 14:00 (LVR6h) and the last VAV duration was for $4 \mathrm{~h}$ from 8:00 until 12:00 (LVR4h), see Table 2. To study the relation between ventilation rates, IAQ and energy savings, each VAV control was modelled separately in IDA ICE 4.

Also, to consider the IAQ when using the VAV system in terms of concentrations of indoor air pollutant gases, for example, $\mathrm{CO}_{2}$ and VOCs, an analytical model for all systems was applied. The aim was to investigate whether the IAQ with decreased ventilation rate is acceptable when occupants arrive home. In addition, the thermal inertia of the building and its influence on the design (maximum) heating power was calculated.

The building had two room-heating systems including ventilation radiator and under-floor heating. In order to investigate whether the type of heating system has any influence on energy savings with VAV control, two cases were considered. First, the building was modelled with under-floor heating in all three floors with both CAV and VAV systems. Then, all heating systems were changed to ventilation radiators on all floors, and simulations were run for both the CAV and VAV systems.

\section{Results}

The results of this study are presented in two parts, the first part deals with the IAQ when decreasing the ventilation air and the second part shows results of energy savings.

\section{$I A Q$}

In this study, the IAQ was investigated in terms of mean age of air, concentration decay and pollutant concentration level $\left(\mathrm{CO}_{2}\right.$ and VOCs) for different mixed ventilation rates. The main focus was on the time when the occupants arrive home, at 18:00.

\section{Mean age of air and theoretical freshness} efficiency. To evaluate the VAV system with different strategies, mean age of air as an indicator of the freshness of indoor air was considered at 18:00. In IDA ICE 4, mean age of air is a measure of how long an average air molecule has spent in the building based on the ideal (full) mixing concept. Mean age of air is calculated from the concentration decay in outgoing air. If a zone is ventilated only by outside air and is at steady state, this number is always equal to the nominal time constant $\tau_{n}$, see equation (1). Mean age of air is an important parameter when assessing IAQ in terms of freshness of air. The higher the age of the air, the more stale or stuffy air would be present in the room. Figure 5 shows the simulation results of how mean age of air would vary during a weekday for different modelled duration periods of VAV. As can be seen, the highest mean age of air was 3.7 h at 18:00 when using LVR10h.

$$
\tau_{n}=\frac{V}{q}
$$

The freshness efficiency $\left(f_{\varepsilon}\right)$ was defined by the authors as a measure of the performance of the VAV system with respect to mean age of air in the room. This term expresses how the freshness of air is perceived as occupants enter home. The theoretical freshness efficiency represents the relation between nominal time 


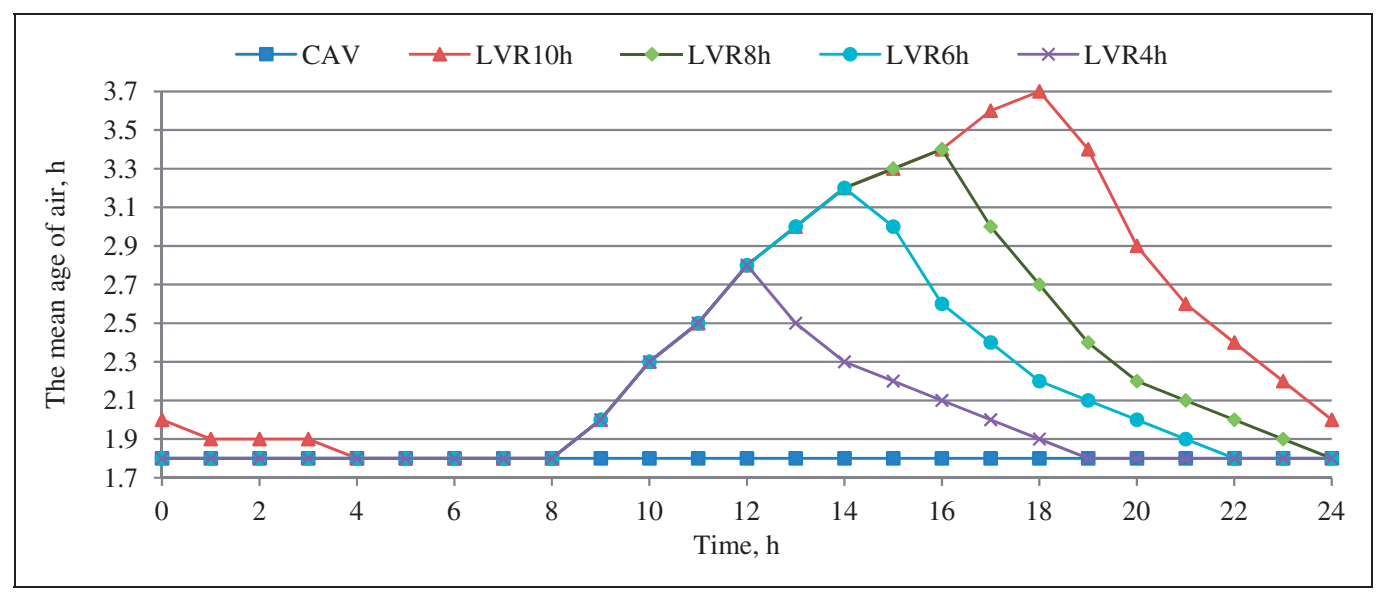

Figure 5. Variation of mean age of air during a weekday as function of different proposed VAV periods. CAV: constant air volume; VAV: variable air volume; LVR: low ventilation rate.

Table 3. Theoretical freshness efficiency and mean age of air for different VAV rates.

\begin{tabular}{lccccc}
\hline & CAV & LVR4h & LVR6h & LVR8h & LVR10h \\
\hline Ventilation rate at 18:00, $\mathrm{h}^{-1}$ & 0.55 & 0.55 & 0.55 & 0.55 & 0.55 \\
Nominal time constant $\left(\tau_{n}\right)$ at 18:00, h & 1.80 & 1.80 & 1.80 & 1.80 & 1.80 \\
Mean age of air at 18:00 $(\bar{\tau}), \mathrm{h}$ & 1.80 & 1.90 & 2.20 & 2.70 & 3.70 \\
Theoretical freshness efficiency $\left(f_{\varepsilon}\right), \%$ & 100.0 & 94.7 & 82.8 & 66.7 & 48.7 \\
\hline
\end{tabular}

CAV: constant air volume; VAV: variable air volume; LVR: low ventilation rate.

constant $\left(\tau_{n}\right)$ at 18:00 and mean age of air $(\bar{\tau})$ at the same time when occupants arrive home. Mean age of air at 18:00 is a result of dynamic calculation during which the ventilation flow rate has been changed from low $\left(0.1001 \cdot \mathrm{s}^{-1} \cdot \mathrm{m}^{-2}\right)$ to high $\left(0.3751 \cdot \mathrm{s}^{-1} \cdot \mathrm{m}^{-2}\right)$. It is called theoretical because of consideration of full mixing and ideal flow concepts. Theoretical freshness efficiency can thus be represented by equation (2).

$$
f_{\varepsilon}=\frac{\tau_{n}}{\bar{\tau}} \cdot 100 \%
$$

For a perfect mixing CAV ventilation system, the theoretical freshness efficiency obtains its maximum possible value of $100 \%$. Table 3 shows mean age of air and theoretical freshness efficiency for different modelled systems.

As can be seen, a higher mean age of air (more than twice the nominal time constant) and lower theoretical freshness efficiency were a result of longer duration with low ventilation rate, that is, LVR10h. Hence, in order to have better IAQ in terms of mean age of air and freshness when occupants arrive home, it is recommended to implement LVR8h, LVR6h or LVR4h.
Concentration decay. The ventilation efficiency can also be measured by concentration decay. For perfect mixing, $63 \%$ of the pollutants would have left the room after a period of $\tau_{n}(1.8 \mathrm{~h})$ from the initial concentration, and after $4 \tau_{n}(7.2 \mathrm{~h})$ this value would be increased to $98 \%$. Equations (3a) and $(3 b)^{23}$ show how the concentration level $c$ in a ventilation system with time constant $\tau_{n}$ is related to the real time $t$. Equations (3a) and (3b) are obtained from mass balance equation taking into account concentration variation over time in a ventilated room with perfect mixing.

$$
\begin{aligned}
& -\frac{d c}{d t}=\frac{1}{\tau_{n}} \cdot c \\
& c=c_{0} \cdot e^{-t / \tau_{n}}
\end{aligned}
$$

The theoretical concentration decay for different mixed airflow rates based on equation (3) is shown in Figure 6. In Figure 6, the indoor concentration is expressed as the ratio of the initial concentration. An exposure impulse was released at 11:00, that is $7 \mathrm{~h}$ before occupants arrive home. As can be seen, after $4 \tau_{n}$, that is, $7 \mathrm{~h}$, the concentration level for LVR $10 \mathrm{~h}$ was still $15 \%$ of the initial value; however, for the CAV system only $2 \%$ of the initial value remained inside the room. 
VOC concentration. The average VOC concentration in dwellings is about $0.1 \mathrm{mg} \cdot \mathrm{m}^{-3}$ corresponding to a generation of $20 \mathrm{mg} \cdot \mathrm{h}^{-1}$. 9 The maximum allowable VOC concentration in indoor air is $0.1 \mathrm{ppm} .{ }^{9}$ Equation (4) shows how the VOC concentration from building materials could vary as a function of number of air changes per hour and emission rates. ${ }^{23}$ Compared with equation (3) this equation has an additional term for internal concentration generation, $\dot{m}$.

$$
c=c_{o} \cdot e^{-n t}+\frac{\dot{m}}{q}\left(1-e^{-n t}\right)
$$

Figure 7 shows the concentration level of VOCs from building materials when using LVR10h and LVR8h. As can be seen, VOC concentration increased with decreasing ventilation rate and after $4 \mathrm{~h}$ of reduction in ventilation rate, at 12:00, the concentration started to exceed the maximum allowed value, that is, $0.1 \mathrm{ppm}$. Then, the concentration started to decrease from $0.14 \mathrm{ppm}$ at 18:00 due to increased ventilation rate. However, the recommended allowable VOC concentration in a room is $0.10 \mathrm{ppm}$, and it would take approximately $1 \mathrm{~h}$ to reach this acceptable level after increasing the ventilation rate. This time is shown in red lines in Figure 7. Hence, to avoid this inconvenient time, and to provide a better IAQ when occupants arrive home at 18:00, it is better to return back to the normal flow rate before occupants arrive home, that is, use LVR8h, see Figure 7.

$\mathrm{CO}_{2}$ concentration. In addition to VOCs from building materials, $\mathrm{CO}_{2}$ concentration was considered

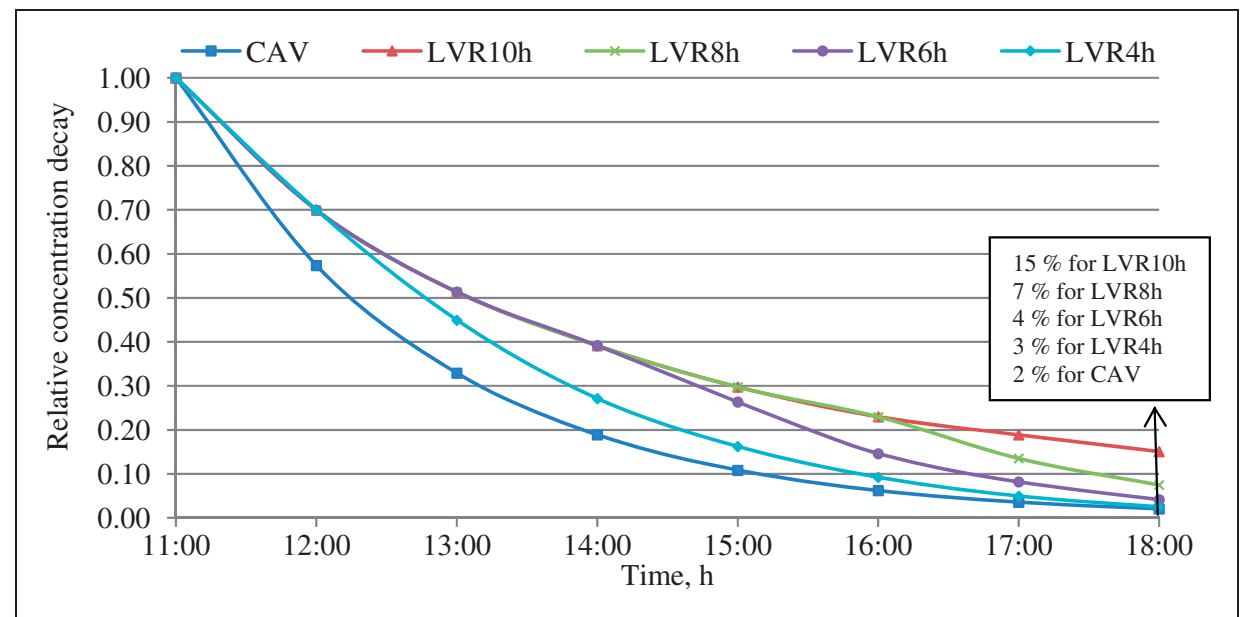

Figure 6. Relative concentration decay for different VAV durations showing the concentration levels during $7 \mathrm{~h}$ before 18:00, that is, when occupants arrive home.

CAV: constant air volume; VAV: variable air volume.

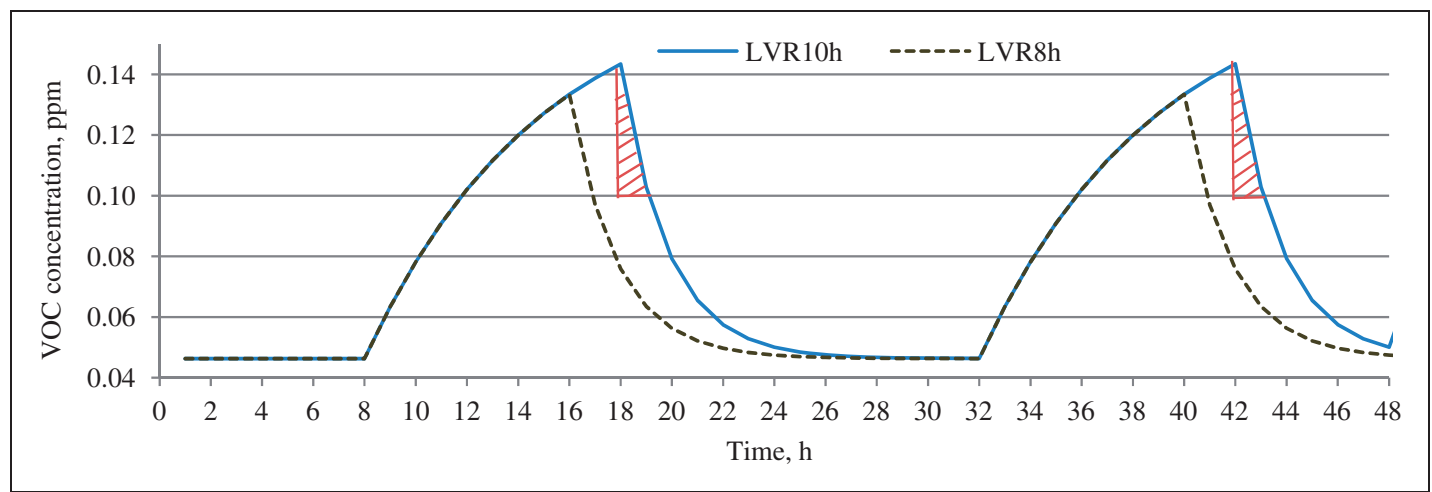

Figure 7. VOC concentration in a room during 2 subsequent days for LVR8h and LVR10h showing the influence of flow rate reduction during unoccupancy on VOC concentration; the periods for LVR10h with greater concentration than allowable when occupants are home are marked in red lines.

VOC: volatile organic compound. 


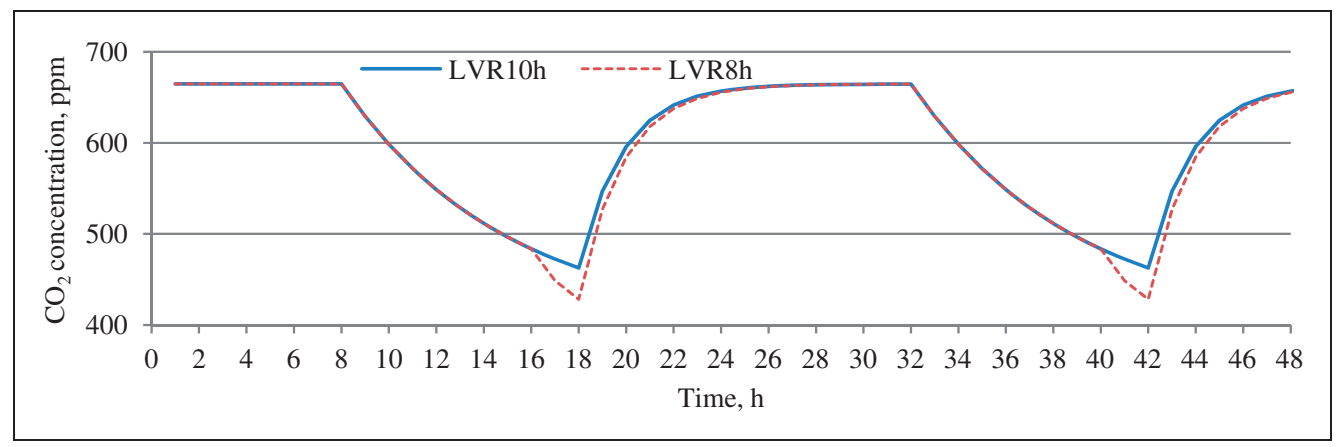

Figure 8. Variation of $\mathrm{CO}_{2}$ concentration in a room for 2 subsequent days based on the presence of occupants and ventilation rate for LVR10h and LVR8h.

in order to evaluate the IAQ for a VAV system. With a $\mathrm{CO}_{2}$ generation of $0.03 \mathrm{~kg} \cdot \mathrm{h}^{-1}$ per person in low to normal activity, ${ }^{24}$ and $400 \mathrm{ppm}$ concentration in outdoor air, the variation of $\mathrm{CO}_{2}$ was calculated using equation (5).

$$
c=c_{o} \cdot e^{-n t}+\left(c_{\text {inlet }}+\frac{\dot{m}}{q}\right)\left(1-e^{-n t}\right)
$$

The results for the LVR8h and LVR10h systems are shown in Figure 8. As can be seen, the level of $\mathrm{CO}_{2}$ concentration never exceeded the maximum allowable value, that is, $1000 \mathrm{ppm}$, which is due to the lack of main pollutant source, that is, occupants in the room, when the ventilation rate was decreased in the middle of the day.

\section{Energy savings with demand control}

Heating power and energy savings with VAV were investigated in terms of the influence on heating requirements for ventilation and space heating.

Influence on heating requirements. In the IAQ part, it was revealed that LVR8h provided better conditions for IAQ compared with LVR10h. The following results are mainly presented for the LVR8h system.

IDA ICE 4 simulation showed that LVR8h decreased the heating required for ventilation and electricity for the ventilation fan up to $20 \%$ and $30 \%$, respectively. Total monthly heating demand including ventilation and space heating for the CAV, LVR8h and LVR10h systems are shown in Figure 9. Simulations showed that by using LVR8h, the annual heating demand decreased by $14 \%$ from $4624 \mathrm{kWh}$ to $3969 \mathrm{kWh}$. The results of total annual energy consumption and savings are presented in Table 4 separately for LVR8h, LVR10h and CAV. As can be seen, the total energy consumption including total heating demand, domestic hot water and ventilation fan was reduced

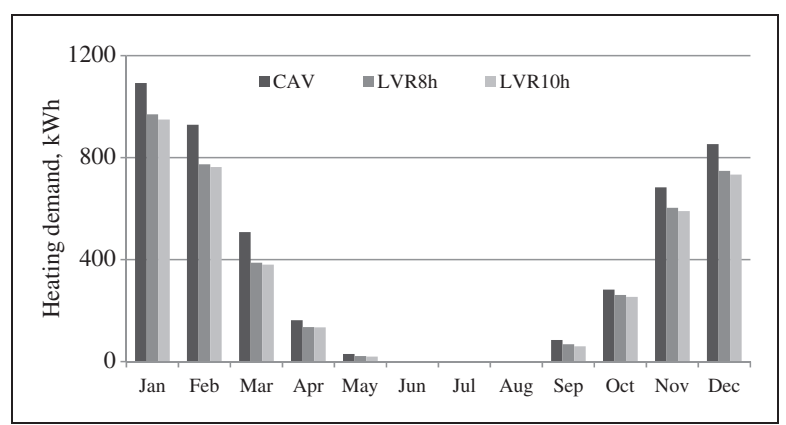

Figure 9. Monthly heating demand with CAV, LVR8h and LVR10h.

CAV: constant air volume.

by $10 \%$ from $52 \mathrm{kWh} \cdot \mathrm{m}^{-2}$ to $47 \mathrm{kWh} \cdot \mathrm{m}^{-2}$ for the LVR8h system compared with CAV. Domestic hot water consumption was estimated from heat pump electricity consumption during summer months, the only reason that the heat pump was providing the heating was because of DHW consumption during this period. In addition, the consumption of the ventilation fan was achieved by knowing the specific fan power, which was $0.9 \mathrm{~kJ} \cdot \mathrm{m}^{-3}$. The reduction in fan power and thus used energy was one-third of the power of the flow variation, as shown in equation (6).

$$
P_{0.100}=P_{0.375} \cdot\left(\frac{q_{0.100}}{q_{0.375}}\right)^{3}
$$

Influence on design power. When decreasing the ventilation rate, the total specific heat loss $\left(Q_{\text {tot }}\right)$ decreased, and as a result the time constant related to the building thermal inertia increased. The time constant represents a simplified quantification of the building's thermal inertia, which is the ratio of available heat capacity in the building $\left(m \cdot c_{h}\right)$ to the total specific heat loss through the building, see equation (7). The total 
Table 4. Energy consumption and savings with LVR10h, LVR8h and CAV systems.

\begin{tabular}{|c|c|c|c|}
\hline & CAV & LVR8h (saving in \%) & LVR10h (saving in \%) \\
\hline Heating requirements for ventilation, $\mathrm{kWh}$ & 2651 & $2132(20)$ & $2041(23)$ \\
\hline Heating demand for ventilation + space heating, $\mathrm{kWh}$ & 4624 & $3969(14)$ & $3885(16)$ \\
\hline Ventilation fan power, $\mathrm{kWh}$ & 473 & $328(30)$ & $292(38)$ \\
\hline Domestic hot water, $\mathrm{kWh}$ & 3200 & $3200(-)$ & $3200(-)$ \\
\hline Total energy consumption, $\mathrm{kWh} \cdot \mathrm{m}^{-2}$ & 52 & $47(10)$ & $46(12)$ \\
\hline
\end{tabular}

CAV: constant air volume.

Table 5. Energy demand in building with different heating systems, that is, ventilation radiator and under-floor heating with CAV, LVR8h and LVR10h systems.

\begin{tabular}{|c|c|c|c|c|}
\hline Heating system & CAV & $\begin{array}{l}\text { LVR8h, } \\
\text { (saving in \%) }\end{array}$ & $\begin{array}{l}\text { LVR10h, } \\
\text { (saving in \%) }\end{array}$ & $\begin{array}{l}\text { BBR requirements } \\
\text { in climate zone } 3\end{array}$ \\
\hline $\mathrm{UFH}+$ Ventilation radiator, $\mathrm{kWh} \cdot \mathrm{m}^{-2}$ & 52 & $47(10)$ & $46(12)$ & 55 \\
\hline Ventilation radiator, $\mathrm{kWh} \cdot \mathrm{m}^{-2}$ & 49 & $46(6)$ & $45(8)$ & 55 \\
\hline $\mathrm{UFH}, \mathrm{kWh} \cdot \mathrm{m}^{-2}$ & 57 & $52(9)$ & $50(14)$ & 55 \\
\hline
\end{tabular}

CAV: constant air volume; UFH: under-floor heating.

heat capacity depends on the individual material characteristics, mass $\left(m_{\mathrm{i}}\right)$ and individual heat capacities $\left(c_{h_{\mathrm{i}}}\right)$. In a newly built Swedish building, the time constant would be approximately 5 days. ${ }^{24}$

$$
\tau_{b}=\frac{\Sigma\left(m_{\mathrm{i}} \cdot c_{h_{\mathrm{i}}}\right)}{Q_{\mathrm{tot}}}
$$

The longer the time constant in a building, the more thermally heavy is the building, and as a result the building is less sensitive to outdoor temperature variations. ${ }^{25}$ This would reduce the requirements on heat distribution system and power supply. The time constant shows how rapidly a temperature change would occur based on an exponential decay function, see equation (8). As indicated by equation (8), if the external temperature is changed step-wise, the internal temperature would decrease by $63 \%$ compared with the initial temperature after one time constant, $\tau_{\mathrm{b}}$.

$$
T=T_{0} \cdot e^{-t / \tau_{\mathrm{b}}}
$$

By increasing the time constant, the thermal inertia for both LVR10h and LVR8h caused the temperature to change more slowly than for the CAV system.

With the LVR8h system, the time constant increased by $9.3 \%$ compared with the CAV system. This enhancement not only influenced the indoor temperature but also the design outdoor temperature $\left(T_{\mathrm{DOT}}\right)$ and hence the design (maximum) heating power $\left(P_{\text {design }}\right)$. In Stockholm, the design outdoor temperature with $\tau_{\mathrm{b}}=5$ days is $-14.8^{\circ} \mathrm{C} .{ }^{24}$ This value changed to $-14.5^{\circ} \mathrm{C}$ with increased time constant of LVR8h. Calculation based on equation (9) showed that the maximum heating power could be decreased by $9.9 \%$ for LVR8h.

$$
P_{\text {design }}=Q_{\text {tot }} \cdot\left(T_{\text {indoor }}-T_{\text {DOT }}\right)
$$

The influence of heating system type for energy savings with a VAV system. In order to investigate the influence on energy savings of a VAV system the building was modelled with both CAV and VAV and different types of heating systems. In the first scenario, it was assumed that the heating system consisted of ventilation radiators on all floors, and in the second scenario, the building was modelled with underfloor heating everywhere. Results were later compared with a combination of heating, that is, under-floor heating on first floor and ventilation radiator on the second and third floors. Simulation results are presented in Table 5. As can be seen, when using CAV, the modelled annual energy consumption was the lowest with ventilation radiators, that is, $49 \mathrm{kWh} \cdot \mathrm{m}^{-2}$. After implementing the LVR8h system, the energy requirements when using ventilation radiators was reduced to $46 \mathrm{kWh} \cdot \mathrm{m}^{-2}$, a saving of $6 \%$. Simulations showed that the energy demand $\left(57 \mathrm{kWh} \cdot \mathrm{m}^{-2}\right)$ in the building modelled with only under-floor heating and CAV was higher than the $\mathrm{BBR}^{3}$ limited value $\left(55 \mathrm{kWh} \cdot \mathrm{m}^{-2}\right.$ in climate zone 3 including Stockholm). The reason could be a longer 
Table 6. Energy savings and indoor air quality for different lengths of VAV compared with CAV.

\begin{tabular}{|c|c|c|c|c|c|}
\hline & CAV & LVR4h & LVR6h & LVR8h & LVR10h \\
\hline Mean ventilation rate weighted over a day, $\mathrm{h}^{-1}$ & 0.55 & 0.48 & 0.45 & 0.42 & 0.38 \\
\hline Relative ventilation rate (compared with $0.55 \mathrm{~h}^{-1}$ ) & 1.00 & 0.87 & 0.82 & 0.76 & 0.70 \\
\hline Space and ventilation heating demand including ventilation fan power, $\mathrm{kWh} /$ year & 5097 & 4668 & 4491 & 4297 & 4177 \\
\hline Savings in space and ventilation heating including ventilation fan power, $\%$ & - & 8.4 & 11.8 & 15.7 & 18.0 \\
\hline Mean age of air at 18:00, $\mathrm{h}$ & 1.8 & 1.9 & 2.2 & 2.7 & 3.7 \\
\hline VOC concentration at $18: 00, \mathrm{ppm}$ & 0.046 & 0.048 & 0.055 & 0.076 & 0.143 \\
\hline Relative VOC concentration (compared with $0.046 \mathrm{ppm}$ ) & 1.00 & 1.04 & 1.20 & 1.65 & 3.11 \\
\hline Increase in time constant $\left(\tau_{\mathrm{b}}\right), \%$ & - & 4.1 & 6.7 & 9.3 & 10.3 \\
\hline Decrease in design (maximum) heating power, $\%$ & - & 4.4 & 7.2 & 9.9 & 11.0 \\
\hline
\end{tabular}

CAV: constant air volume; VAV: variable air volume; VOC: volatile organic compound.

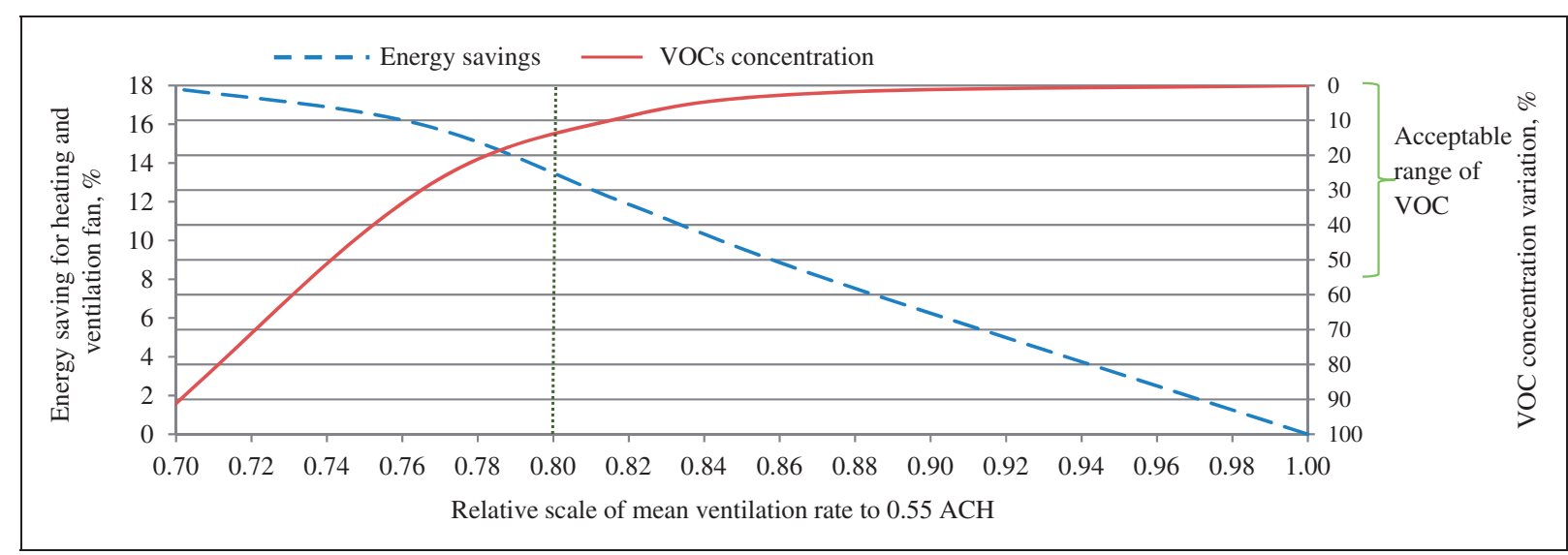

Figure 10. Energy savings and VOC variation in percent of total concentration for different mean ventilation flow rates. VOC: volatile organic compound.

heating season, higher heat loss through the floor and slow thermal control when sudden temperature changes occur. However, after implementing the LVR8h system the building with UFH met the Swedish requirements. In the building modelled with under-floor heating and LVR10h system, the energy savings were more significant, that is, $14 \%$, see Table 5 .

\section{Discussion}

IAQ should be considered when energy is saved by decreasing ventilation rate, as poor IAQ may cause health problems. $^{26}$ In this paper, three parameters, that is, mean age of air, VOCs and $\mathrm{CO}_{2}$ as indicators of IAQ were studied. Table 6 shows the summary of energy savings and IAQ for different proposed VAV durations. As shown, for LVR10h the VOCs were above the acceptable level $(0.1 \mathrm{ppm})$ and mean age of air in this system was two times higher than the nominal time constant, that is $1.8 \mathrm{~h}$.

Results on how energy savings and VOC concentration, as an indicator of IAQ, change with the mean airflow rate are presented in Figure 10. IAQ decreases with reduced ventilation rate and energy savings increase, an acceptable balance has to be found. The figure shows that decreasing the mean ventilation rate to $80 \%$ of the CAV system (LVR4h and LVR6h) did not influence VOC concentration very much, that is, concentration increased by $13 \%$ of the total variation and energy savings were $13 \%$ of reference consumption. However, decreasing the ventilation rate over $80 \%$ of CAV (LVR8h and LVR10h) would give a sudden increase in VOC concentration level and the energy saving was only a few percent higher $(5 \%)$. As shown in Figure 10, the VOC concentration variations lower than $55 \%$ of the total enabled the IAQ to be within an acceptable range, ${ }^{9}$ that is, VOC concentration was lower than $0.1 \mathrm{ppm}$. This point would correspond to an energy saving of $17 \%$ and decreased ventilation by $74 \%$ of the constant rate. Hence, by decreasing mean ventilation by $74 \%$ (decreasing the ventilation rate for approximately $8 \mathrm{~h}$ ) not only acceptable IAQ can be achieved but also an energy-efficient building concept can be maintained. Hence, it should be noted that decreasing the ventilation 
rate to $0.11 \cdot \mathrm{s}^{-1} \cdot \mathrm{m}^{-2}$ would limit duration when IAQ is to be considered. The study showed that every litre per second reduction in ventilation rate would cause 0.5 $1.4 \%$ energy savings for ventilation heating and ventilation fan consumption.

In order to investigate the real long-term performance of the systems, implementation in an occupied building is recommended. Also, in the proposed DCV, the amount of ventilation decreases/increases with the same rate in all zones of the building. The ventilation demand was, however, not the same in all rooms. For instance, during the night, bedrooms would be more occupied and would need more ventilation than living rooms. The ventilation rate could thus be decreased to the minimum level of $0.11 \cdot \mathrm{s}^{-1} \cdot \mathrm{m}^{-2}$ in living rooms during the night (part of night) and to the same rate in bedrooms during the day (part of day). Hence, in order to increase efficiency of the system, future research could investigate IAQ and energy savings in a local demand ventilation system, which increases/decreases the ventilation rate based on the presence of the residents.

\section{Conclusion}

The purpose of this study was to investigate consequences on IAQ and energy savings when ventilation supply air was controlled by demand. Swedish regulations allow a drop of ventilation rate from $0.351 \cdot \mathrm{s}^{-1} \cdot \mathrm{m}^{-2}$ to $0.101 \cdot \mathrm{s}^{-1} \cdot \mathrm{m}^{-2}$ during unoccupancy, but for how many hours this is allowable remains unclear. Four VAV durations were therefore proposed in a new Swedish dwelling with a CAV system. During weekdays the occupants leave home at 8:00 and return at 18:00. In the first strategy, the ventilation rate was decreased during the whole unoccupancy (low ventilation for $10 \mathrm{~h}$ ). In the second scenario, the ventilation was returned to normal flow rate $2 \mathrm{~h}$ before the home was occupied (low ventilation for $8 \mathrm{~h}$ ). For the third and fourth cases, the airflow was returned to normal flow rates 4 and $6 \mathrm{~h}$ before occupants arrived home. The IDA ICE 4 simulation software and an analytical model were used to evaluate each system in terms of IAQ and energy savings.

The results of the study were divided into two parts: the first part dealt with IAQ with decreasing ventilation rate and the second part showed energy savings with a VAV system. The IAQ investigation was based on four parameters:

1. mean age of air;

2. concentration decay;

3. VOC concentration;

4. $\mathrm{CO}_{2}$ concentration.

Results of the first part showed that when the reduced ventilation rate covered the entire time of unoccupancy,
$10 \mathrm{~h}$, the VOC concentration was unacceptable, and mean age of air was high $(3.7 \mathrm{~h})$ when occupants arrived home. In order to take this inconvenience into account, it was suggested to increase the ventilation rate to normal requirements $2 \mathrm{~h}$ before the home was occupied. However, it should be noticed that the current research was undertaken in a new building, where the VOC concentration would normally be higher than in an older building. So, it might not be necessary to increase the ventilation rate to the same extent before occupants arrive home in older buildings, and some more savings could be achieved.

In the second part, energy savings were studied after decreased heating demand and increased thermal inertia of the building. Results showed that the total savings from ventilation fan and heating was $16 \%$ when the airflow was reduced for $8 \mathrm{~h}$ during unoccupancy. In addition, as a result of increased thermal inertia of the building, the design (maximum) heating power was decreased by $10 \%$ when lowering the ventilation rate for $8 \mathrm{~h}$. Also, the influence of heating system type on energy savings with VAV was studied.

Energy-efficient ventilation considering IAQ is needed when the ventilation rate is adjusted to the occupants' demand. This study is a guideline to encourage the building sector to introduce VAV systems in residential buildings more often than before. Ventilation rates should be according to this report and be decreased when occupants are not present. Naturally, IAQ requirements should always be followed. The result of this study is in line with the European Union goal of reducing the consumption of energy in buildings by $20 \%$ up to 2020 .

\section{Acknowledgements}

We are grateful to the Swedish Energy Agency (Energimyndigheten) and SBUF, The Development Fund of the Swedish Construction Industry for the financial support.

\section{References}

1. Engdahl F and Johansson D. Optimal supply air temperature with respect to energy use in a variable air volume system. Energy Build 2004; 36: 205-218.

2. Aktacir MA, Büyükalaca O and Yılmaz T. Life-cycle cost analysis for constant-air-volume and variable-air-volume airconditioning systems. Appl Energy 2006; 83: 606-627.

3. BBR Swedish Building Regulations: [Online] http://www.boverket. se/ (accessed 2012)

4. United States Environmental Protection Agency. Assessment of $C V$ and $V A V$ ventilation systems and outdoor air control strategies for large office buildings. Washington, DC: United States Environmental Protection Agency, 2000.

5. Laverge J, Van Den Bossche N, Heijmans $\mathrm{N}$ and Janssens A. Energy saving potential and repercussions on indoor air quality of demand controlled residential ventilation strategies. Building Environ 2011; 46: 1497-1503. 
6. Afshari A and Bergsoe NC: Reducing energy consumption for ventilation in dwellings through demand controlled ventilation. In: Proceedings of indoor air 2005, the 10th international conference on indoor air quality and climate, Beijing, China, 4-9 September 2005, pp. 3289-3292.

7. Mortensen DK: Demand controlled ventilation for multi-family dwellings: demand specification and system design. PhD Thesis, Department of Civil Engineering, Technical University of Denmark, Denmark, 2011.

8. Heinonen J and Seppänen OA: Air flows of a demand controlled residential ventilation. In: Proceedings of healthy buildings '94, Budapest, Hungary, 22-25 August 1994, 301-306.

9. Månsson LG and Svennberg SA: Demand controlled ventilating systems: source book. IEA Energy Conservation, Swedish Council for Building Research Stockholm, Sweden, 1992.

10. Emmerich SJ, Mitchell JW and Beckman WA. Demand-controlled ventilation in a multi-zone office building. Indoor Built Environ 1994; 3: 331-340.

11. Nassif N. A robust $\mathrm{CO}_{2}$-based demand-controlled ventilation control strategy for multi-zone HVAC systems. Energy Build 2012; 45: 72-81.

12. Chao CYH and Hu JS. Development of an enthalpy and carbon dioxide based demand control ventilation for indoor air quality and energy saving with neural network control. Indoor Built Environ 2004; 13: 463-475.

13. Xu X and Wang S. An adaptive demand-controlled ventilation strategy with zone temperature reset for multi-zone air-conditioning systems. Indoor Built Environ 2007; 16: 426-437.

14. Hesaraki A and Homberg S. Energy performance of low temperature heating systems in five new-built Swedish dwellings, A case study using simulations and on-site measurements. Build Environ 2013; 64: 85-93.

15. Yang XB, Jin XQ, Du ZM, Fan B and Chai XF. Evaluation of four control strategies for building VAV air-conditioning systems. Energy Build 2011; 43: 414-422.

16. Myhren JA: Potential of ventilation radiators: performance evaluation by numerical, analytical and experimental investigations.
$\mathrm{PhD}$ Thesis in Civil and Architectural Engineering, KTH Royal Institute of Technology, Stockholm, Sweden, 2011.

17. EQUA Simulation AB: [Online] http://www.equa-solutions. co.uk/ (accessed date 1995-2013 EQUA Simulation AB)

18. EQUA Simulation AB: Manual version: 4.0 IDA Indoor Climate and Energy 4.0, September 2009.

19. Kropf $\mathrm{S}$ and Zweifel G: Validation of the building simulation program IDA-ICE according to CEN 13791 "Thermal Performance of Buildings - Calculation of Internal Temperatures of a Room in Summer Without Mechanical Cooling-General Criteria and Validation Procedures", HOCHSCHULE FÜR TECHNIK + ARCHI T EKTUR LUZERN, [Online] http://www.equaonline.com/iceuser/validation/ICE_vs_prEN\%2013791.pdf.

20. Moosberger S: IDA ICE CIBSE-Validation: test of IDA Indoor Climate and Energy version 4.0 according to CIBSE TM33, issue 3. SAP-No.: 1120213, 2007.

21. Validation of IDA Indoor Climate and Energy 4.0 with respect to CEN Standards EN 15255-2007 and EN 15265-2007, Technical report, Equa Simulation AB, Sweden, 2010.

22. Validation of IDA Indoor Climate and Energy 4.0 build 4 with respect to ANSI/ASHRAE Standard 140-2004, Technical report, Equa Simulation Simulation AB, Sweden, 2010.

23. Nilsson PE. Achieving the desired indoor climate, energy efficiency aspects of system design. Lund, Sweden: Studentlitteratur, 2007.

24. Warfvinge C and Dahlblom M. Projektering av VVS-installationer. Lund, Sweden: Studentlitteratur, 2010 (in Swedish).

25. Karlsson J. Possibilities of using thermal mass in buildings to save energy, cut power consumption peaks and increase the thermal comfort. Licentiate Thesis, Lund Institute of Technology, Lund, Sweden, 2012.

26. Fisk JW, Mirer AG and Mendell MJ. Quantitative relationship of sick building syndrome symptoms with ventilation rates. Indoor Air J 2009; 19: 159-165. 